\title{
RESEARCH IN PROGRESS
}

Four graduate students are working full time on these projects. Summarized below are brief descriptions of their research. Also included is a reprint of a recent article in Science magazine which describes recent research on methane oxidation to produce syngas.

\section{Ignition and Extinction}

Thus far we have characterized heterogeneous and homogeneous ignition and extinction in oxidation of $\mathrm{CH}_{4}, \mathrm{C}_{3} \mathrm{H}_{8}, \mathrm{NH}_{3}$, and $\mathrm{CH}_{4}+\mathrm{NH}_{3}$ mixtures, showing that all have analogous bifurcation diagrams but at quite different temperatures and compositions. We shall continue these experiments for other fuels in an effort to categorize homogeneousheterogeneous behavior in many systems. This type of experiment is the starting point for more detailed studies because these experiments give rapid characterization of ignition and extinction characteristics for a particular reaction system and catalyst.

Other oxidants such as $\mathrm{NO}, \mathrm{NO}_{2}$, and $\mathrm{N}_{2} \mathrm{O}$ are being examined. These oxidants can react with fuels as rapidly as $\mathrm{O}_{2}$, and reactions are just as exothermic (we shall dilute with $\mathrm{N}_{2}$ for safety). However, they can have quite different reaction paths and may exhibit different bifurcation behavior. We are especially interested to see whether homogeneous reaction is suppressed with nitrogen containing oxidants, analogous to the boundary layer flames observed with $\mathrm{NH}_{3}+\mathrm{O}_{2}$.

\section{Reactions in Monoliths}

The obvious extension of these experiments on foils and wires is to examine analogous processes in monoliths. Here one has reaction within channels rather than simply in a boundary layer over a flat surface. This situation is essentially two dimensional because of radial and axial variations in both composition and gas temperature. The wall temperature variation should be largely axial except for temperature variations within the catalyst layer on the wall. The advantages of examining monoliths rather than foils are (1) product compositions can be measured because all gases flow uniformly through the monolith and (2) this is the geometry of interest in applications.

In the next generation of experiments we shall use gas cell infrared spectroscopy to characterize products in addition to GC. This has two advantages. First, analysis is very

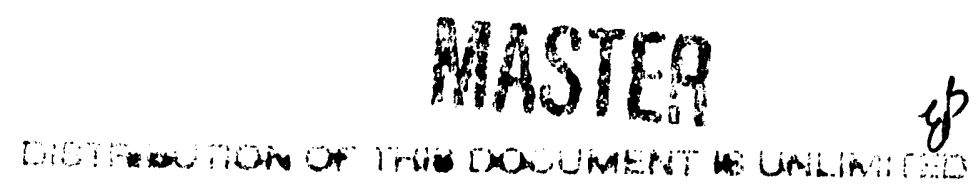


- rapid compared to the 10 min required for GC. By sitting on a single IR peak, analysis of transients will be as rapid as flow conditions permit (several seconds). Several peaks can also be scanned in a few seconds so that the effect of varying flow conditions on transients in reaction rate and selectivity can be monitored on a time scale of seconds. Second, many products of partial oxidation are unstable against reaction. As examples, NO decomposes and oxidizes in the $\mathrm{GC}$ column and reacts readily with liquid $\mathrm{H}_{2} \mathrm{O}$ to form $\mathrm{HNO}_{3}$ (which corrodes most metals), $\mathrm{HCN}$ hydrolyzes, and $\mathrm{HCHO}$ and $\mathrm{HCN}$ polymerize if cooled. Therefore IR analysis is essential for quantitative analysis of some partial oxidation processes on monoliths.

We are exploring systematically the use of monoliths for partial oxidation reactions. Current reactions, $\mathrm{HCN}$ and $\mathrm{NO}$ synthesis and $\mathrm{CH}_{4}$ oxidation, are being extended to other systems of scientific and practical interest. Acetonitrile from ethane and acrylonitrile from propane are obvious examples of ammoxidation, but many hydrocarbon reactions with $\mathrm{O}_{2}$, $\mathrm{N}_{2} \mathrm{O}$, NO, and $\mathrm{NO}_{2}$ can be explored. Catalysts, reactant composition, and monolith temperature are obvious variables to be examined. The simple partial oxidation of alkanes to olefins, alcohols, aldehydes, ketones, acids, $\mathrm{CO}$, and $\mathrm{CO}_{2}$ provides a rich range of system with which to explore uses of catalytic monoliths.

\section{Boundary Layer Reactions}

Here we are interested specifically in characterizing reactions in boundary layers above catalytic surfaces. The crucial issue is the ability to characterize composition and temperature profiles during reaction. This subject underlies the previcus topics in that it looks at the detailed processes which produce ignition and extinction and which determine the rates and selectivities on monoliths.

In addition to LIF, we are attempting to measure boundary layer compositions noninvasively using gas phase infrared spectroscopy. By focussing the IR beam into a slit and passing it over a reacting foil, it should be possible to measure concentrations of various species in the reacting boundary layer. A dual beam system will be used to cancel out background and reactant gases, and this may permit detection of intermediates which do not survive transport through the boundary layer. A variation on this is to search for $\mathbb{I R}$ emission from excited species and measure temperatures within the hot boundary layer. 


\section{Modeling}

Models will be developed simultaneously with each of the above experiments. As we have stressed, each of these experiments is sufficiently complicated that models are necessary to guide experiments in choice of parameters and systems.

The models necessary to describe these experiments are sufficiently complicated that a special effort will continue to develop more efficient methods and algorithms. This will involve both "complete" simulations in which we shall attempt to describe experimental results quantitatively using realistic kinetics and material properties, as well as simpler models designed to determine dominant effects qualitatively.

For two dimensional situations a full finite element or finite difference method will be necessary, although the largest gradients occur in the axial direction, and radial lumping may be possible. These methods will also he necessary for simulation of transients. The reverse flow mode mentioned above is also an interesting situation for detailed modeling.

\section{SUMMARY}

We have an ambitious program to characterize fundamental issues and practical applications of homogeneous-heterogeneous reactions. Fundamental studies of reactions at low pressures and of boundary layer characterization give microscopic information on the processes. Ignition and extinction studies over simple geometries give basic bifurcation behavior with which to characterize multiple steady states and their stabilities and hopefully to identify the types of behavior which may occur. Use of catalytic monoliths will permit examination of the chemical and thermal performance of one of the most important types of geometries in which both types of reaction can occur. Modeling will tie all of these aspects together by showing how individual components interact, predicting performance of monoliths, and providing the framework for translating these ideas into technological contexts. 
STUDENTS SUPPORTED BY THIS GRANT, 1988-present.

\begin{tabular}{|c|c|c|c|c|}
\hline Cheinan Marks & Delaware & 1985-90 & LIF of $\mathrm{OH}$ & NRL \\
\hline Max Song & Beijing & 1986-90 & Modelling H-H Reactions & Mobil Oil \\
\hline Bill Williams & WPI & $1987-911$ & Ignition and Quenching & Dupont \\
\hline $\begin{array}{l}\text { Dan Hickman } \\
\text { (NSF fellow) }\end{array}$ & Iowa State & $1988-92$ & Reactions in Monoliths & Dow \\
\hline Ajit Balakrishna & Bombay & 1989- & \multicolumn{2}{|l|}{ Oscillations in $\mathrm{H}-\mathrm{H}$ Reactions } \\
\hline $\begin{array}{l}\text { Robert Olsen } \\
\text { (Army fellow) }\end{array}$ & $\begin{array}{l}\text { Brandeis } \\
\text { (PhD) }\end{array}$ & $1990-931$ & \multicolumn{2}{|l|}{ Modeling Boundary Flames } \\
\hline Matt Wagner & $\mathrm{CMU}$ & $1987-90$ & Chemistry of C-N-O bonds & Praxair \\
\hline $\begin{array}{l}\text { Marylin Huff } \\
\text { (NDSEG fellow) }\end{array}$ & Texas A\&M & 1990- & \multicolumn{2}{|c|}{ Partial Oxidation on Monoliths } \\
\hline Mike ZumMallen & Illinois & 1990- & \multicolumn{2}{|c|}{ Kinetics and LIF in Combustion } \\
\hline Paul Tournianen & Clarkson & 1991- & \multicolumn{2}{|c|}{ Catalytic Incineration of Organics } \\
\hline Julie Wang & Xinghua & 1992- & \multirow{2}{*}{\multicolumn{2}{|c|}{ Partial Oxidation of Methanol }} \\
\hline Al Dietz & MIT & 1992- & & \\
\hline Eric Olsen & Alabama & 1992- & & \\
\hline
\end{tabular}




\section{PUBLICATIONS FROM THIS RESEARCH}

W. R. Williams, X. Song, M. V. Stenzel, and L. D. Schmidt, "Bifurcation Behavior in Homogeneous-Heterogeneous Combustion: I. Experiments on Pt Foils", Combustion and Flame 84, 265-276 (1991).

X. Song, W. R. Williams, L. D. Schmidt, and R. Aris, "Bifurcation Behavior in Homogeneous-Heterogeneous Combustion: II. Computations in Stagnation Point flow ", Combustion and Flame 84, 277-292 (1991).

X. Song, W. R. Williams, L. D. Schmidt, and R. Aris, "Ignition and Extinction of Homogeneous-Heterogeneous Combustion: $\mathrm{CH}_{4}$ and $\mathrm{C}_{3} \mathrm{H}_{8}$ on $\mathrm{Pt}^{\prime}$, Proceedings of the 23rd International Combustion Institute, 1129-1137 (1990).

L. D. Schmidt and R. Aris, "Dynamics of Catalytic Reactions on Metal Surfaces", pages 201-216 in Unsteady State Processes in Catalysis, VSP Press, Utrecht, Holland (1990).

D. Hickman and L. D. Schmidt, "Modeling Catalytic Gauze Reactors: Ammonia Oxidation", Industrial and Engineering Chemistry Research 30, 50 (1991).

X. Song, L. D. Schmidt, and R. Aris, "The Ignition Criterion for Stagnation-Point Flow: Semenov-Franck-Kamenetski or van't Hoff", Combustion Science and Technology 75, 311 (1991).

X. Song, L. D. Schmidt, and R. Aris, "Steady States and Oscillations in Homogeneousheterogeneous Reaction Systems", Chem. Eng. Sci. 46, 1203-1215 (1991).

C. Marks and L. D. Schmidt, "Hydroxyl Radical Desorption in Catalytic Combustion", Chem. Phys. Letters 178, 358-361 (1991).

M. L. Wagner and L. D. Schmidt, "Adsorption and Decomposition of $\mathrm{H}_{2} \mathrm{NCHO}$, $\mathrm{D}_{2} \mathrm{NCHO}, \mathrm{N}_{2} \mathrm{H}_{4}$, and $\mathrm{NH}_{3}$ on $\mathrm{Rh}(111)$, Surface Science 257, 113-128 (1991).

W. R. Williams, J. Zhao, and L. D. Schmidt, "Ignition and Extinction of Surface and Homogeneous Oxidation of $\mathrm{NH}_{3}$ and $\mathrm{CH}_{4}$ over Pt", AIChE Journal 37, 641-649 (1991).

M. L. Wagner and L. D. Schmidt, "Model Catalytic Oxidation Reactions: Oxygen with $\mathrm{H}_{2}$, $\mathrm{NH}_{3}$, and $\mathrm{N}_{2} \mathrm{H}_{4}$ on $\mathrm{Rh}(111)^{\prime}$, J. Phys. Chem., to be published.

M. ZumMallen, W. R. Williams, L. D. Schmidt, "Steps in the Reaction $\mathrm{H}_{2}+\mathrm{O}_{2} \rightarrow \mathrm{H}_{2} \mathrm{O}$ on Rh: $\mathrm{OH}$ Desorption at High Temperature", J. Phys. Chem., to be published.

D. G. Vlachos, L. D. Schmidt, and R. Aris, "Structures of Small Metal Clusters: Isomerization and Phase Transitions", J. Chem. Phys. 96, 6891 (1992). 
D. A. Hickman and L. D. Schmidt, "The Role of Boundary Layer Mass Transfer in Selectivity of Partial Oxidation, J. Catalysis 136, 300-308 (1992).

W. R. Williams and L. D. Schmidt, "Steps in the Reaction $\mathrm{H}_{2}+\mathrm{O}_{2} \rightarrow \mathrm{H}_{2} \mathrm{O}$ on Pt: $\mathrm{OH}$ Desorption at High Temperature", J. Phys. Chem. 96, 5922 (1992).

V. J. Kwasniewski and L. D. Schmidt, "Steps in the Reaction $\mathrm{H}_{2}+\mathrm{O}_{2} \rightarrow \mathrm{H}_{2} \mathrm{O}$ on Pt: Low Temperature Reactions", J. Phys. Chem. 92, 5931 (1992).

M. L. Wagner and L. D. Schmidt, "Model Catalytic Oxidation Reactions: Oxygen with $\mathrm{H}_{2}$, $\mathrm{NH}_{3}$, and $\mathrm{N}_{2} \mathrm{H}_{4}$ on $\mathrm{Rh}(111)$ ", J. Phys. Chem., to be published.

L. D. Schmidt and D. A. Hickman, "Surface Chemistry and Engineering of HCN Synthesis", to be published.

R. J. Olsen, W. R. Williams, L. D. Schmidt, and R. Aris, "Dynamics of HomogeneousHeterogeneous Reactors", Chem. Eng. Sci. 47, 2505-2510 (1992).

D. A. Hickman and L. D. Schmidt, "Syngas Production by Direct Oxidation of Methane on Monoliths", J. Catalysis 138, 267-282 (1992).

R. J. Olsen, L. D. Schmidt, and R. Aris, "Effects of Velocity on HomogeneousHetertogeneous Ignition and Extinction", Combustion Science and Technology, submitted.

M. L. Wagner and L. D. Schmidt, "Surface Chemistry of C-N-O Bonds on Noble Metals", in preparation.

D. A. Hickman and L. D. Schmidt, "Syngas Production by Direct Oxidation of Methane", ACS Proceedings, to be published.

D. A. Hickman and L. D. Schmidt, "Elementary Steps in Methane Oxidation on Pt and Rh: Reactor Modeling at High Temperature", A.I.Ch.E Journal, to be published.

D. A. Hickman and L. D. Schmidt, "Syngas Formation by Direct Oxidation of Methane over Rh Monoliths", Catalysis Letters 17, 223 (1993).

D. A. Hickman and L. D. Schmidt, "Syngas Formation by Direct Catalytic Oxidation of Methane", Science 259, 343-346 (1993).

D. A. Hickman, M. Huff, and L. D. Schmidt, "Alternative Catalyst Supports for HCN Synthesis and $\mathrm{NH}_{3}$ Oxidation", Industrial and Engineering Chemistry, to be published.

D. G. Vlachos, L. D. Schmidt, and R. Aris, "Ignition and Extinction of Flames Near Surfaces: $\mathrm{H} 2$ in Air", Combustion and Flame, to be published.

A. Balakrishna, L. D. Schrnidt, and R. Aris, "Ignition and Extinction of Methane-Propane Flames in Air", submitted. 

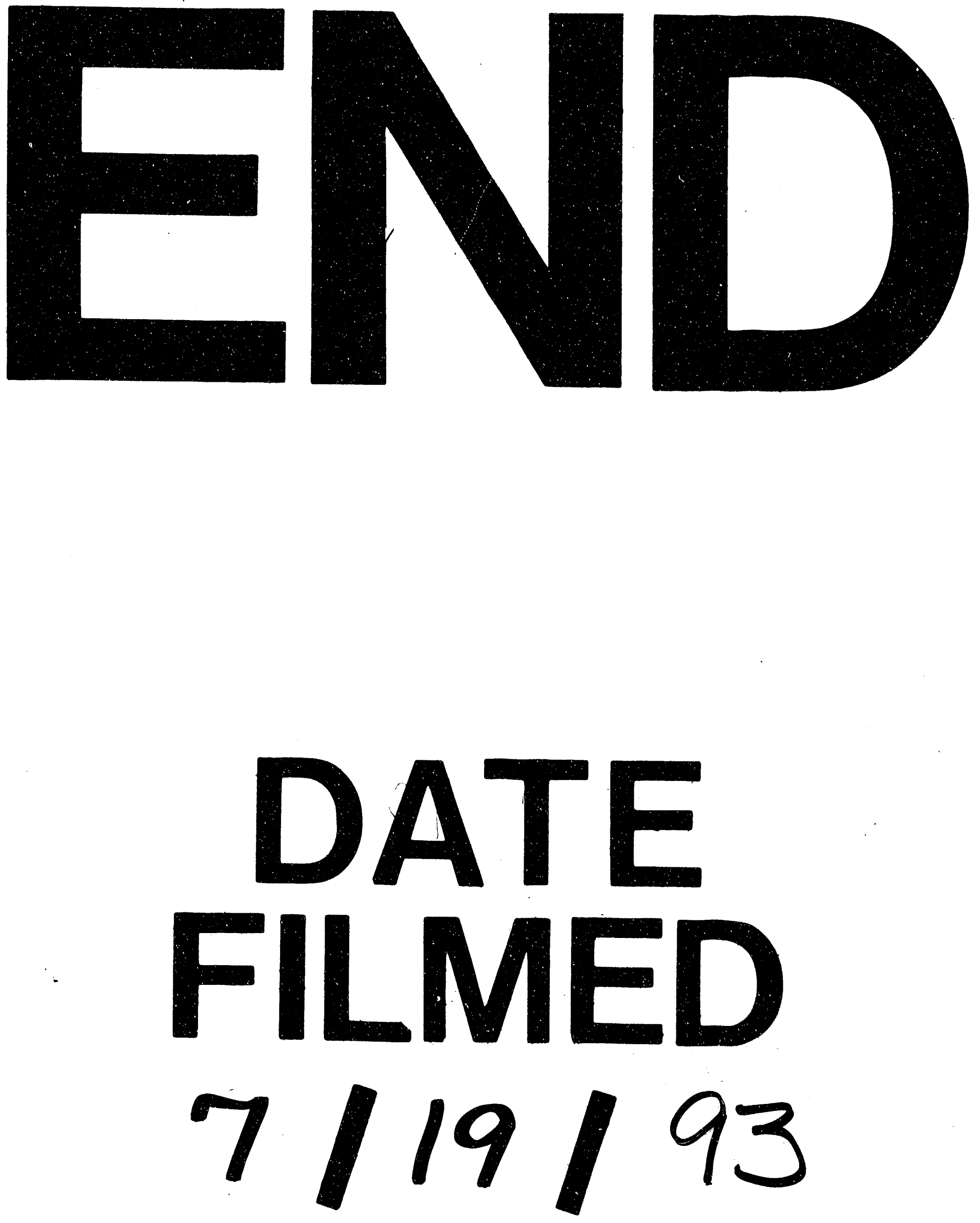


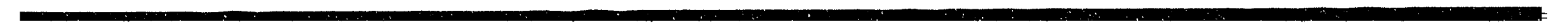

